\title{
Right Trisectionectomy and Caval Reconstruction with Peritoneal Patch Under Short Total Vascular Exclusion for Hepatocellular Carcinoma with Tumoral Thrombus in Suprahepatic Vena Cava
}

\author{
Safi Dokmak, MD, Béatrice Aussilhou, MD, Tiziana Marchese, MD, Nizar Kardoun, MD, François Cauchy, MD, \\ Anne Sophie Schneck, MD, and Olivier Soubrane, MD
}

Department of HPB Surgery and Liver Transplantation, Beaujon Hospital, Clichy, France

\begin{abstract}
Background. Hepatocellular carcinoma (HCC) can be complicated by major vascular invasion, and resection can be beneficial in some patients. ${ }^{1}$ Some of these patients are traditionally operated under total vascular exclusion (TVE), refrigeration, extracorporeal circulatory bypass, and cardiac surgery, with high morbidity and mortality. ${ }^{2}$ However, HCC thrombi are not adherent to the venous wall, and with advances in surgical techniques, resection can be simplified and performed during short-duration TVE alone. Patients who need resection under any degree of TVE represent $<5 \%$ of our hepatectomies.

Patient and Methods. A 59-year-old male patient was admitted for management of a right large HCC (developed on a metabolic syndrome without cirrhosis). After 12 months of treatment, HCC progressed after arterial chemoembolization followed by antiangiogenic treatment, with tumoral thrombus extension to the intrathoracic vena cava up to the right atrium. Surgical resection under TVE and intrathoracic control of the vena cava was decided. Liver transection was performed with intermittent clamping of the hepatic pedicle and low central venous pressure. During $25 \mathrm{~min}$ of TVE and vascular remplissage, resection was completed with complete thrombectomy and reconstruction of the vena cava with a peritoneal patch. ${ }^{3}$
\end{abstract}

Electronic supplementary material The online version of this article (https://doi.org/10.1245/s10434-018-6414-9) contains supplementary material, which is available to authorized users.

(C) Society of Surgical Oncology 2018

First Received: 30 October 2017;

Published Online: 13 March 2018

S. Dokmak, MD

e-mail: safi.dokmak@bjn.aphp.fr
Results. Surgery lasted $330 \mathrm{~min}$, with blood loss of $500 \mathrm{ml}$ and transfusion of 2 units of blood. Postoperative course was uneventful with 10-day hospital stay. Four months after resection, the patient is well with no disease recurrence.

Conclusion. As surgical techniques improve, complicated liver resection can be performed during short-duration total vascular exclusion.

DISCLOSURE The authors have no conflicts of interest in relation to this article.

\section{REFERENCES}

1. Kokudo T, Hasegawa K, Yamamoto S, Shindoh J, Takemura N, Aoki $\mathrm{T}$, et al. Surgical treatment of hepatocellular carcinoma associated with hepatic vein tumor thrombosis. $J$ Hepatol 2014;61(3):583-8.

2. Pesi B, Giudici F, Moraldi L, Montesi G, Romagnoli S, Pinelli F, et al. Hepatocellular carcinoma on cirrhosis complicated with tumoral thrombi extended to the right atrium: results in three cases treated with major hepatectomy and thrombectomy under hypothermic cardiocirculatory arrest and literature review. World J Surg Oncol 2016 12;14:83.

3. Dokmak S, Aussilhou B, Sauvanet A, Nagarajan G, Farges O, Belghiti J. Parietal peritoneum as an autologous substitute for venous reconstruction in hepatopancreatobiliary surgery. Ann Surg 2015;262(2):366-71. 